\title{
Autonomous Satellite Operations Via Secure Virtual Mission Operations Center
}

Eric Miller

General Dynamics Advanced Information Systems, Vandenberg Air Force Base, California

Phillip E. Paulsen

Glenn Research Center, Cleveland, Ohio

Michael Pasciuto

Goddard Space Flight Center, Greenbelt, Maryland 


\section{NASA STI Program . . . in Profile}

Since its founding, NASA has been dedicated to the advancement of aeronautics and space science. The NASA Scientific and Technical Information (STI) program plays a key part in helping NASA maintain this important role.

The NASA STI Program operates under the auspices of the Agency Chief Information Officer. It collects, organizes, provides for archiving, and disseminates NASA's STI. The NASA STI program provides access to the NASA Aeronautics and Space Database and its public interface, the NASA Technical Reports Server, thus providing one of the largest collections of aeronautical and space science STI in the world. Results are published in both non-NASA channels and by NASA in the NASA STI Report Series, which includes the following report types:

- TECHNICAL PUBLICATION. Reports of completed research or a major significant phase of research that present the results of NASA programs and include extensive data or theoretical analysis. Includes compilations of significant scientific and technical data and information deemed to be of continuing reference value. NASA counterpart of peer-reviewed formal professional papers but has less stringent limitations on manuscript length and extent of graphic presentations.

- TECHNICAL MEMORANDUM. Scientific and technical findings that are preliminary or of specialized interest, e.g., quick release reports, working papers, and bibliographies that contain minimal annotation. Does not contain extensive analysis.

- CONTRACTOR REPORT. Scientific and technical findings by NASA-sponsored contractors and grantees.
- CONFERENCE PUBLICATION. Collected papers from scientific and technical conferences, symposia, seminars, or other meetings sponsored or cosponsored by NASA.

- SPECIAL PUBLICATION. Scientific, technical, or historical information from NASA programs, projects, and missions, often concerned with subjects having substantial public interest.

- TECHNICAL TRANSLATION. Englishlanguage translations of foreign scientific and technical material pertinent to NASA's mission.

Specialized services also include creating custom thesauri, building customized databases, organizing and publishing research results.

For more information about the NASA STI program, see the following:

- Access the NASA STI program home page at http://www.sti.nasa.gov

- E-mail your question via the Internet to help@ sti.nasa.gov

- Fax your question to the NASA STI Help Desk at 443-757-5803

- Telephone the NASA STI Help Desk at 443-757-5802

- Write to: NASA Center for AeroSpace Information (CASI) 7115 Standard Drive Hanover, MD 21076-1320 


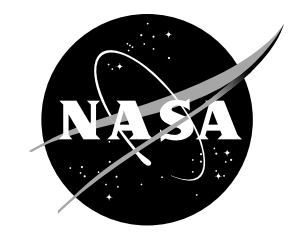

\section{Autonomous Satellite Operations Via Secure Virtual Mission Operations Center}

\section{Eric Miller}

General Dynamics Advanced Information Systems, Vandenberg Air Force Base, California

Phillip E. Paulsen

Glenn Research Center, Cleveland, Ohio

Michael Pasciuto

Goddard Space Flight Center, Greenbelt, Maryland

Prepared for the

2010 International Geoscience and Remote Sensing Symposium

cosponsored by the Institute of Electrical and Electronics Engineers, Geoscience and Remote Sensing Society

Honolulu, Hawaii, July 25-30, 2010

National Aeronautics and

Space Administration

Glenn Research Center

Cleveland, Ohio 44135 
This report is a formal draft or working paper, intended to solicit comments and ideas from a technical peer group.

Trade names and trademarks are used in this report for identification only. Their usage does not constitute an official endorsement, either expressed or implied, by the National Aeronautics and Space Administration.

Level of Review: This material has been technically reviewed by technical management.

Available from

NASA Center for Aerospace Information 7115 Standard Drive

Hanover, MD 21076-1320
National Technical Information Service 5301 Shawnee Road Alexandria, VA 22312

Available electronically at http://gltrs.grc.nasa.gov 


\title{
Autonomous Satellite Operations Via Secure Virtual Mission Operations Center
}

\author{
Eric Miller \\ General Dynamics Advanced Information Systems \\ Vandenberg Air Force Base, California 93437 \\ Phillip E. Paulsen \\ National Aeronautics and Space Administration \\ Glenn Research Center \\ Cleveland, Ohio 44135 \\ Michael Pasciuto \\ National Aeronautics and Space Administration \\ Goddard Space Flight Center \\ Greenbelt, Maryland 20771
}

\begin{abstract}
The science community is interested in improving their ability to respond to rapidly evolving, transient phenomena via autonomous rapid reconfiguration, which derives from the ability to assemble separate but collaborating sensors and data forecasting systems to meet a broad range of research and application needs. Current satellite systems typically require human intervention to respond to triggers from dissimilar sensor systems. Additionally, satellite ground services often need to be coordinated days or weeks in advance. Finally, the boundaries between the various sensor systems that make up such a Sensor Web are defined by such things as link delay and connectivity, data and error rate asymmetry, data reliability, quality of service provisions, and trust, complicating autonomous operations. Over the past 10 years, researchers from the NASA Glenn Research Center (GRC), General Dynamics, Surrey Satellite Technology Limited (SSTL), Cisco, Universal Space Networks (USN), the U.S. Geological Survey (USGS), the Naval Research Laboratory, the DoD Operationally Responsive Space (ORS) Office, and others have worked collaboratively to develop a "virtual" mission operations capability. Called "VMOC" (Virtual Mission Operations Center), this new capability allows crosssystem queuing of dissimilar mission unique systems through the use of a common security scheme and published application programming interfaces (APIs). Collaborative VMOC demonstrations over the last several years have supported the standardization of spacecraft to ground interfaces needed to reduce costs, maximize space effects to the user, and allow the generation of new tactics, techniques and procedures that lead to responsive space employment.
\end{abstract}

\section{Towards Operationally Responsive Space: An Emerging Architecture}

Development of an operationally responsive space architecture is a technically difficult task. With notably few exceptions, space platform architectures are paired with mission specific ground infrastructures designed to optimize the interface. While these stovepipes are efficient within themselves, they don't allow for a common user access, prioritization, multi-mission management, or cross platform connectivity. Improvements are needed across the ground infrastructure to derive the capability and status of mission asset (such as constellation health), current tasking levels, ground station availability, and impacts due to operations. Without detailed knowledge of the platforms state and capabilities, rapid theater level tasking would need to be limited to reduce risk to the platform. Responsive space operations need robust tools that can track current conditions, receive real-time requests from the field, predict future mission capabilities, correct for limitations, and automate information flow. This is particularly relevant when dealing with dynamically taskable assets operating in dissimilar environments (on the ground, at sea, in the air, near space, and in space. Collaborative operations across multiple sensor systems will provide timely access to effects that have never been available through the current stovepipe architectures and will lead to more and better science for the community.

The Virtual Mission Operations Center is one tool that is being developed to support dynamically taskable assets that are the key to the success of responsive space operations. 


\section{VMOC Background}

The Virtual Mission Operations Center (VMOC) system is a software based platform to incubate, mature, and transition new and relevant technologies and concepts of operations via continuous operational experimentation. It was originally sponsored by the NASA Earth Science Technology Office (ESTO) and is now sponsored by the Office of Naval Research (ONR) and the Office of the Secretary of Defense (OSD) to explore and document the capabilities related to Operationally Responsive Space (ORS), multi-sensor networks, and user collaboration. The Naval Research Laboratory (NRL) has been designated program manager for the current initiative. The VMOC system has already participated in several demonstrations, experiments, and exercises that have helped to shape and mature the technology.

The original VMOC concept began in 2000 and by 2004 had four teams focusing on individual aspects of responsive space. The NASA team addressed Internet Protocol (IP) based command and control, the AF Space Battle Lab team focused on prioritized multi mission operations, the Army Space Battle Lab team addressed theater level platform access, and the NRL team addressed broad based user access, collaboration, and operational experimentation.

In FY2008 the teams merged under the NRL to focus on integration of all the elements into a system of systems addressing the tasking portion of Responsive Space Tasking, Collection, Processing, Exploitation, and Dissemination (TCPED).

In FY2010 the VMOC begins operations supporting two missions: the TacSat-4 communications relay and the ORS-1 Electro-Optical (EO) and Infrared (IR) sensor platform. In both cases, user requests are entered via a web-based interface, vetted by known prioritization schemes, and provided status on their task through all steps of the process from schedule to upload, tasking, downlink, and processing.

\section{VMOC System}

Responsive space requires all system segments to work together effectively to support operational users. The intent is to begin standardizing the spacecraft to ground interfaces needed to reduce costs, maximize space effects to the user, and allow the generation of tactics techniques and procedures (TTPs) that lead to responsive space employment. The VMOC system is comprised of three large components designated as tactical, mission, and apportionment and is represented in Figure 1. Each component provides specific capabilities and is tailored to a specific user base. The tactical component is designed to support multi-sensor access and collaboration among a diverse user community. The mission component provides support for platform management, sensor access, data storage, processing, and sharing while the apportionment component provides automated support, with man on the loop for user prioritization of ORS assets.

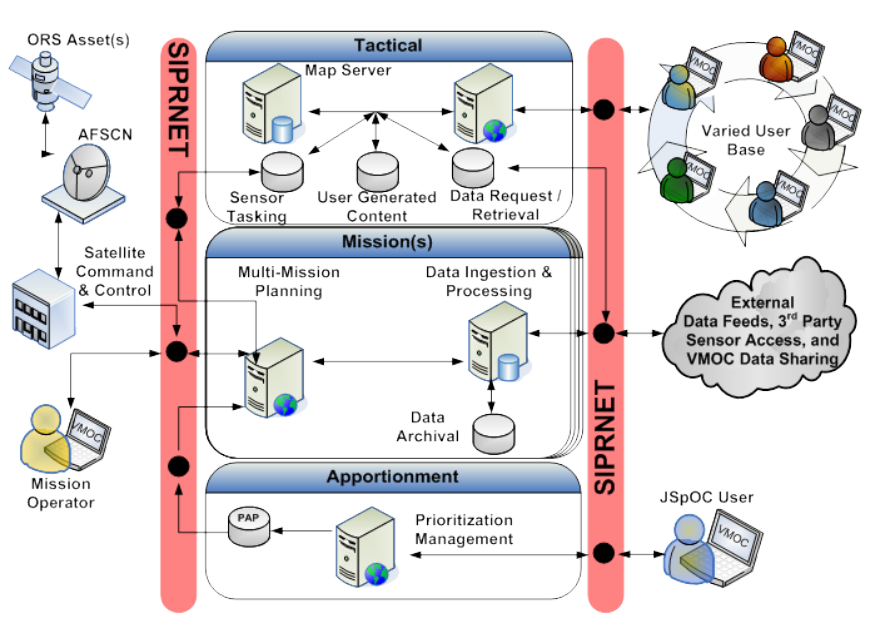

Figure 1.-VMOC system of systems.

Specifics of each component are as follows:

\section{Tactical VMOC: Enable the Users}

The new operationally responsive system architecture must encompass a robust community of networked sensors and users. This tiering of a wide variety of sensors and people will result in synergies that do not emerge in small user communities or monolithic systems. In addition, this architecture will spur the development and maturity of more complex operations concepts that will accentuate and prioritize the strengths and uniqueness of the collaborative systems and their diverse user base. Therefore, a system is needed that can lower the barriers of entry for access to space based capabilities and explore, develop, and mature new methods of employment within a multi-sensor framework. The tactical component of VMOC was developed to meet that need.

The tactical server allows non-space savvy users the ability to:

- Task, track, and receive data from multiple ORS sources

- Manage user accounts and assign privileges

- Subscribe to data feeds from air, surface, human, and space sources including ORS assets

- Use collaboration tools, establish workgroups, and work in virtual teams and

- Interface with the apportionment and mission VMOC elements.

\section{Mission VMOC: Mange the Sensors}

Scalability, reduction of non-recurring costs, and responsive access to dedicated capabilities are the main principles that will allow for successful execution of the new initiative. The adherence to these principles is never more critical than in the operation of combined system assets. Specifically, the addition of new satellites into the community of sensors and users must not come at an unreasonable cost in time, money, or manpower. These new satellites must cleanly integrate within 
an architecture that exposes capabilities to a rich set of systems and users. To do this, the system must embrace the tenets of a service oriented architecture, automation, standard processing, and standard interfaces. Therefore, a system is needed that permits this addition and exposure of capabilities without negatively impacting the architecture or the user base. The mission component was designed to meet that need.

The mission server provides services for tasking sensors, ingesting data feeds from third party providers, data processing and archiving, and data sharing. In this architecture there can be more than one Mission VMOC allowing for the tasking, data collection, and processing of multiple assets via web services. The services it provides includes but it not limited to:

- Multi mission planning

- Interface to multiple command generation systems

- Data ingestion and archiving

- Data processing and data feed generation as well as

- Interface with tactical users and space controllers

\section{Apportionment VMOC: Establish the Rules}

Currently, operations of space assets are the responsibility of the individual system owners. The current process, while highly effective for controlling and managing individual space systems, needs to be reconsidered in an operationally responsive construct, which aims to reduce the requirementstasking-effects cycle from 24 hours to hours or even minutes. With that in mind, the Apportionment VMOC provides the tools needed to automate the prioritization and allocation process of dynamically taskable assets. The VMOC Apportionment services allow collaborative science mission teams to dynamically apportion and prioritize collected assets. The services it provides include:

- Interfaces with data users to request asset apportionment

- Establishes standing apportionment requests

- Accounts for maintenance outages

- Supports apportionment of multiple ORS assets for effects based operations and

\section{VMOC Strategic Roadmap}

The VMOC strategic roadmap prioritized the efforts needed to achieve ORS initial operational capability by 2010 . The strategic direction of the VMOC over the past two years was categorized by integration, operational experimentation, and advocacy, leading to a transition to operations with the launch of two diverse missions.

\section{Integration}

The last four years have seen several complimentary VMOC architectures with each focusing on a specific aspect of netcentric operations. In FY08 the VMOC integration team began the integration of the three primary VMOC components: tactical, apportionment, and mission with a goal to mature the components to TRL 7. The integration encompassed a multiyear development effort with a near term focus on capabilities that resonated with the mission community.

\section{Operational Experimentation}

At the heart of VMOC development was a strategy to execute an operational experimentation plan that includes VMOC training, limited objective experiments, and at least one large-scale exercise. This approach exposed select technologies in a relevant environment that served to educate and involve the community at large in the maturity of the VMOC initiative. The data collected from these venues was used to mature the concept of operations and net centric technologies needed in the responsive space environment. The successful system of systems demonstration in 2008 lead to the ORS Office selecting the VMOC as the planning, tasking, scheduling, and sensor visualization tool for its 2015 Ground System Enterprise.

\section{Autonomous Satellite Operations Experiment}

The VMOC represents a completely new approach to integrated mission operations. By utilizing open standards and published APIs, VMOC allows mission unique systems to readily adapt and perform cross-platform queuing. VMOC also allows the use of a single network security solution and includes tools for things like the calculation and visualization of satellite orbital mechanics. Mission rules, codified within VMOC, prevent inadvertent or inappropriate operations (such as slewing a sensor across the sun) and provide prioritization at the user and command levels. VMOC can also provide standard telemetry displays (virtual strip charts, gas gauges, etc...) and annunciation. During a 2008 to 2009 GRC experiment, Earthquake sensors provided by the USGS were used to trigger VMOC negotiations with flight systems provided by Surrey Satellite Technology Limited (SSTL) and ground systems provided by Universal Space Networks (in Alaska, Hawaii, and Australia). Delay Tolerant Networking (DTN) protocols, codified by GRC and SSTL, were also integrated into all systems.

Existing world-wide, ground-based earthquake sensor systems, fed to a threshold monitoring system, were used to trigger $\mathrm{VMOC}$ to begin the process of selecting appropriate satellite sensor systems (based on sensor type and orbital mechanics). Once the sensors were selected, VMOC autonomously negotiated machine-to-machine with their ground operations systems to determine sensor availability and resource limitations (satellite power, etc...). With satellite system negotiations successfully completed, VMOC then began the process of determining which commercial ground stations would be appropriate for up linking commands, and, later, down linking resulting data. Once selections were completed, VMOC then autonomously negotiated machine-tomachine with ground service provider systems to obtain the 
services necessary, and to configure their antennas and equipment to track and communicate with the spacecraft sensor systems. Finally, to minimize the impact of link delays and disruptions (common with satellite systems in low Earth orbit), new, "delay tolerant network" (DTN) protocols were utilized. These protocols autonomously compensated for rate mismatches between the high rate space-to-ground links and the lower rate ground connections as well as intermittent losses between system nodes.

\section{Experiment Conclusions}

Using triggers from the earthquake sensors (intentionally set at modest threshold values), satellite sensor collects and ground system operations were autonomously negotiated and implemented. All of the systems worked as predicted. In addition, the DTN protocols allowed both proactive and reactive fragmentation of large data files (hyperspectral images) as well as reliable, sequential data drops over multiple ground stations.

\section{VMOC Way Forward}

The VMOC's path to space operations has followed a multiyear process that initiated from a need to make space capabilities more accessible to users and to dynamically manage space systems consistent with increasingly dynamic operations. There have been many lessons learned in developing a transformational space sensor tasking system that taxed current concepts of operations, external interfaces, and deployment strategies. With the technical hurtles being worked, the team also had to deal with new training and accreditation processes. VMOC is a core element of the ORS Ground System Enterprise and will provide a scalable, dynamic, and flexible set of services to support and further the ORS vision. With the launch of the ORS-1 and TacSat-4 in November and December 2010, the VMOC will provide the only mechanism to task the missions. For TacSat-4, the VMOC is deployed at the Naval Research Lab and the NRL's Blossom Point Satellite Operations Center (SOC) facility. For ORS-1 the VMOC is being deployed at SOC 11 at Schriever Air Force Base. The apportionment operations are at the STRATCOM's Global Network Operations, and Joint Functional Component Command for Intelligence, Surveillance, and Reconnaissance (JFCC ISR)/Space chains respectively.

\section{Bibliography}

Ivancic, William, et al., "Large-File Transfers from Space Using Multiple Ground Terminals and Delay Tolerant Networking," IEEE GlobeCom 2010, December 2010.

Ivancic, William, et al., "Virtual Mission Operations of Remote Sensors with Rapid Access To and From Space," AIAA-2010 2305, Huntsville, AL, SpaceOps 2010, April 26-30, 2010.

Miller, Eric, et al., "VMOC and ORS Ground System Enterprise Lessons Learned," AIAA Responsive Space Conference No. 8, April 2010.

Walke, Jon G., et al., "Secure Autonomous Automated Scheduling (SAAS) Phase 1 Final Report," NASA Contractor Report NASA/CR - 2010-216097, March 2010.

Miller, Eric, et al., "Virtual Mission Operations Center: Transforming the conduct of space based operations," International Command and Control Research and Technology Symposium, June 2009.

Miller, Eric, et al., "Virtual Mission Operations Center and ORS Ground System Enterprise," AIAA Responsive Space Conference No. 7, April 2009.

Miller, Eric, et al., Virtual Mission Operations Center Explicit Access to Small Satellites by a Net Enabled User Base," ESA Small Satellite Systems and Services Symposium, May 2008.

Miller, Eric, et al., "Virtual Mission Operations Center Integration: The Next Step in Development and Experimentation," AIAA Responsive Space Conference No. 6, April 2008.

Ivancic, William, et al., "Secure, Autonomous, Intelligent Controller for Integrating Distributed Sensor Webs," IEEE Aerospace Conference, March 2007.

Ivancic, William, et al. "Secure, Network-Centric Operations of a Space-Based Asset: Cisco Router in Low Earth Orbit (CLEO) and Virtual Missions Operations Center (VMOC)," NASA/TM2005-213556, May 2005. 


\begin{tabular}{|c|c|c|}
\hline \multicolumn{2}{|c|}{ REPORT DOCUMENTATION PAGE } & $\begin{array}{l}\text { Form Approved } \\
\text { OMB No. 0704-0188 }\end{array}$ \\
\hline \multicolumn{3}{|c|}{ 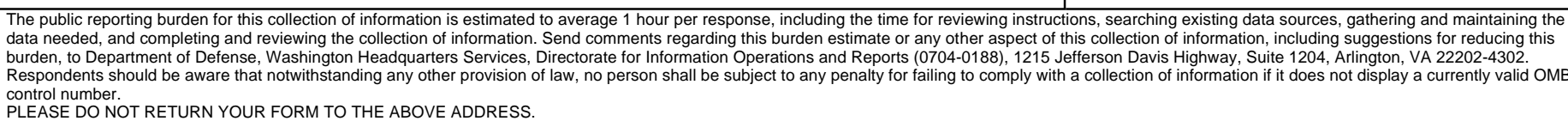 } \\
\hline $\begin{array}{l}\text { 1. REPORT DATE (DD-MM-YYYY) } \\
01-01-2011\end{array}$ & $\begin{array}{l}\text { 2. REPORT TYPE } \\
\text { Technical Memorandum }\end{array}$ & 3. DATES COVERED (From - To) \\
\hline \multirow{3}{*}{\multicolumn{2}{|c|}{$\begin{array}{l}\text { 4. TITLE AND SUBTITLE } \\
\text { Autonomous Satellite Operations Via Secure Virtual Mission Opera }\end{array}$}} & 5a. CONTRACT NUMBER \\
\hline & & 5b. GRANT NUMBER \\
\hline & & 5c. PROGRAM ELEMENT NUMBER \\
\hline \multirow{3}{*}{\multicolumn{2}{|c|}{$\begin{array}{l}\text { 6. AUTHOR(S) } \\
\text { Miller, Eric; Paulsen, Phillip, E.; Pasciuto, Michael }\end{array}$}} & 5d. PROJECT NUMBER \\
\hline & & 5e. TASK NUMBER \\
\hline & & $\begin{array}{l}\text { 5f. WORK UNIT NUMBER } \\
\text { WBS 430728.02.01.02 }\end{array}$ \\
\hline \multicolumn{2}{|c|}{$\begin{array}{l}\text { 7. PERFORMING ORGANIZATION NAME(S) AND ADDRESS(ES) } \\
\text { National Aeronautics and Space Administration } \\
\text { John H. Glenn Research Center at Lewis Field } \\
\text { Cleveland, Ohio 44135-3191 }\end{array}$} & $\begin{array}{l}\text { 8. PERFORMING ORGANIZATION } \\
\text { REPORT NUMBER } \\
\text { E-17548 }\end{array}$ \\
\hline \multirow{2}{*}{\multicolumn{2}{|c|}{$\begin{array}{l}\text { 9. SPONSORING/MONITORING AGENCY NAME(S) AND ADDRESS(ES) } \\
\text { National Aeronautics and Space Administration } \\
\text { Washington, DC 20546-0001 }\end{array}$}} & $\begin{array}{l}\text { 10. SPONSORING/MONITOR'S } \\
\text { ACRONYM(S) } \\
\text { NASA }\end{array}$ \\
\hline & & $\begin{array}{l}\text { 11. SPONSORING/MONITORING } \\
\text { REPORT NUMBER } \\
\text { NASA/TM-2011-216944 }\end{array}$ \\
\hline \multicolumn{3}{|c|}{$\begin{array}{l}\text { 12. DISTRIBUTIONIAVAILABILITY STATEMENT } \\
\text { Unclassified-Unlimited } \\
\text { Subject Category: } 17 \\
\text { Available electronically at http://gltrs.grc.nasa.gov } \\
\text { This publication is available from the NASA Center for AeroSpace Information, 443-757-5802 }\end{array}$} \\
\hline
\end{tabular}

\section{SUPPLEMENTARY NOTES}

\section{ABSTRACT}

The science community is interested in improving their ability to respond to rapidly evolving, transient phenomena via autonomous rapid reconfiguration, which derives from the ability to assemble separate but collaborating sensors and data forecasting systems to meet a broad range of research and application needs. Current satellite systems typically require human intervention to respond to triggers from dissimilar sensor systems. Additionally, satellite ground services often need to be coordinated days or weeks in advance. Finally, the boundaries between the various sensor systems that make up such a Sensor Web are defined by such things as link delay and connectivity, data and error rate asymmetry, data reliability, quality of service provisions, and trust, complicating autonomous operations. Over the past ten years, researchers from the NASA Glenn Research Center (GRC), General Dynamics, Surrey Satellite Technology Limited (SSTL), Cisco, Universal Space Networks (USN), the U.S. Geological Survey (USGS), the Naval Research Laboratory, the DoD Operationally Responsive Space (ORS) Office, and others have worked collaboratively to develop a "virtual” mission operations capability. Called "VMOC” (Virtual Mission Operations Center), this new capability allows cross-system queuing of dissimilar mission unique systems through the use of a common security scheme and published application programming interfaces (APIs). Collaborative VMOC demonstrations over the last several years have supported the standardization of spacecraft to ground interfaces needed to reduce costs, maximize space effects to the user, and allow the generation of new tactics, techniques and procedures that lead to responsive space employment.

\section{SUBJECT TERMS}

Autonomy; Communications; Networking; Security; Operations

\begin{tabular}{|c|c|c|c|c|}
\hline \multicolumn{3}{|c|}{ 16. SECURITY CLASSIFICATION OF: } & \multirow{2}{*}{$\begin{array}{l}\text { 17. LIMITATION OF } \\
\text { ABSTRACT } \\
\text { UU }\end{array}$} & \multirow{2}{*}{$\begin{array}{l}\text { 18. NUMBER } \\
\text { OF } \\
\text { PAGES } \\
10\end{array}$} \\
\hline $\begin{array}{l}\text { a. REPORT } \\
\mathrm{U}\end{array}$ & $\begin{array}{l}\text { b. ABSTRACT } \\
U\end{array}$ & $\begin{array}{l}\text { c. THIS } \\
\text { PAGE } \\
\text { U }\end{array}$ & & \\
\hline
\end{tabular}

19a. NAME OF RESPONSIBLE PERSON STI Help Desk (email:help@sti.nasa.gov) 19b. TELEPHONE NUMBER (include area code) 443-757-5802 

